\title{
A cannabis oracle? Delphi method not a substitute for randomized controlled trials of cannabinoids as therapeutics
}

Kevin P. Hill ${ }^{1,2^{*}}$ and Donald I. Abrams ${ }^{3}$

\begin{abstract}
Background: With millions of people using cannabinoids to treat a host of medical conditions, clinicians want guidance on how to utilize cannabinoids as pharmacotherapy in their practices. The Delphi method is a systematic, interactive forecasting method that aims to develop consensus best practices where guidelines are not available.

Body: A multidisciplinary group of global cannabinoid experts utilized a modified Delphi process to develop three protocols for the dosing and administration of cannabinoids to treat chronic pain. Two protocols recommend cannabidiol (CBD), for which there is limited evidence as an analgesic, starting well below doses required for other indications. Guidance on prescribing CBD for pain may demonstrate consensus recommendations based upon suboptimal evidence.
\end{abstract}

Conclusion: Consensus processes like the Delphi method are well-meaning, but they are not a substitute for rigorous RCTs with large sample sizes, adequate duration, and standardized outcome measures.

Keywords: Medical cannabis, Chronic pain, Cannabidiol, CBD, Tetrahydrocannabinol, THC, Delphi process

\section{Background}

The rate and scale of cannabinoid science has not been able to keep pace with the intense clinical interest in cannabinoids. With millions of people using cannabinoids to treat myriad medical conditions, clinicians are clamoring for guidance on how to utilize cannabinoids as pharmacotherapy in their practices. Recent data suggest that three-quarters of medical trainees want more cannabis education than they currently receive (St. Pierre et al. 2020). The use of cannabis and related compounds as medicine remains a controversial topic; thus, limited clinical practice guidelines exist.

This comment refers to the article available online at https://doi.org/10.1186/ s42238-021-00073-1.

*Correspondence: Khill1@bidmc.harvard.edu

${ }^{1}$ Division of Addiction Psychiatry, Beth Israel Deaconess Medical Center,

Grzymish 133, 330 Brookline Avenue, Boston, MA 02215, USA

Full list of author information is available at the end of the article
The Delphi method is a structured communication technique that was developed as a systematic, interactive forecasting method. A panel of experts answers questionnaires in two or more rounds. Anonymized summaries of responses are provided to the experts after each round and the experts are encouraged to revise their answers in light of the others' replies. The range of answers converges toward consensus and the process is stopped after a predefined stop criterion is met.

\section{Main text}

In this issue of Journal of Cannabis Research, a multidisciplinary group of global experts in the field of cannabinoids utilized a modified Delphi process to develop three protocols for the dosing and administration of cannabinoids to treat chronic pain (Bhaskar et al. 2021). The protocols-routine, conservative, and

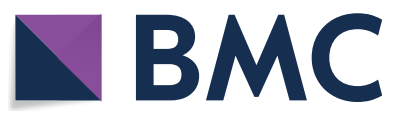

(c) The Author(s) 2021. Open Access This article is licensed under a Creative Commons Attribution 4.0 International License, which permits use, sharing, adaptation, distribution and reproduction in any medium or format, as long as you give appropriate credit to the original author(s) and the source, provide a link to the Creative Commons licence, and indicate if changes were made. The images or other third party material in this article are included in the article's Creative Commons licence, unless indicated otherwise in a credit line to the material. If material is not included in the article's Creative Commons licence and your intended use is not permitted by statutory regulation or exceeds the permitted use, you will need to obtain permission directly from the copyright holder. To view a copy of this licence, visit http://creativecommons.org/licenses/by/4.0/. 
rapid-were designed based upon the desired time to achieve clinical effects. In the routine and conservative protocols, CBD-predominant cannabinoid products are started at a dose of CBD $5 \mathrm{mg}$ twice daily and titrated up to CBD $40 \mathrm{mg}$ daily, at which time small doses of THC are started. In the rapid protocol, patients are started on cannabinoids with THC and CBD in a $1: 1$ ratio at $2.5-5 \mathrm{mg}$ of each cannabinoid one to two times daily and titrated to a maximum dose of THC $40 \mathrm{mg}$ daily.

Guidance on prescribing CBD for pain illustrates consensus recommendations based upon suboptimal evidence. Despite hypothetical and preclinical rationales for CBD as an analgesic (Pisanti et al. 2017), limited clinical evidence, in the form of data from randomized clinical trials (RCTs), exists. Most RCT data for cannabinoids in pain is for THC alone or products with THC and CBD, such as nabiximols, or whole-plant cannabis. CBD alone has been shown to be effective in patients with pain from neurologic injuries, kidney transplantation, neuropathy, and fibromyalgia (Wade et al. 2003; Cunetti et al. 2018; Xu et al. 2019; Van De Donk et al. 2019). However, these studies utilized small sample sizes and disparate outcome measures. Similar trials of CBD for pain from Crohn's disease and generalized chronic pain did not show benefit (Naftali et al. 2014; Notcutt et al. 2004, Cunetti et al. 2018; Capano et al. 2020), however, leaving a clear need for larger, rigorously designed trials of CBD for chronic pain.

Bhaskar and colleagues attempt to expand the limited evidence for $\mathrm{CBD}$ as an analgesic even further by providing dosing recommendations for CBD without presenting additional data. Starting at CBD $5 \mathrm{mg}$ twice daily and titrating to $40 \mathrm{mg}$ daily, while unlikely to lead to side effects, is also quite a bit lower than CBD dosing used, albeit for a variety of indications, in other clinical trials. Several rigorously designed RCTs utilized CBD doses in the range of several hundred to over a thousand milligrams. Why CBD was chosen as the initial intervention when the existing data demonstrates analgesic effects from THC-based interventions seems puzzling. Despite the input from the Delphi experts, at the end of the day, the clinician may be better off deciding which cannabinoid he or she hopes will provide analgesia and then dosing that cannabinoid appropriately by assessing the patient's response.

\section{Conclusion}

There is a clear need for clinical guidance on the use of cannabinoids as pharmacotherapy for chronic pain. Consensus processes like the Delphi method are wellmeaning, but they are not a substitute for rigorous RCTs with large sample sizes, adequate duration, and standardized outcome measures. All key stakeholders must share the goal of using RCTs to determine cannabinoid efficacy in chronic pain, and those who can contribute to this goal should do so. We need the best science we can produce.

\section{Abbreviations}

CBD: Cannabidiol; THC: Tetrahydrocannabinol.

\section{Acknowledgements}

Dr. Hill recently co-authored a book on cannabis for Wolters-Kluwer and he has received royalties from them. He is also a consultant to Greenwich Biosciences. Dr. Abrams is a scientific advisor to Cannformatics, Lumen, and Maui Grown Therapies.

\section{Authors' contributions}

Both authors conceptualized the manuscript and participated in the writing. The authors read and approved the final manuscript.

Funding

The authors received no funding for this work.

Availability of data and materials

Not applicable.

\section{Declarations}

Ethics approval and consent to participate

Not applicable.

Consent for publication

Not applicable.

\section{Competing interests}

The authors declare that they have no competing interests.

\section{Author details}

'Division of Addiction Psychiatry, Beth Israel Deaconess Medical Center, Grzymish 133, 330 Brookline Avenue, Boston, MA 02215, USA. ${ }^{2}$ Department of Psychiatry, Harvard Medical School, Boston, USA. ${ }^{3}$ Department of Medicine, University of California, San Francisco, USA.

Received: 30 April 2021 Accepted: 14 May 2021

Published online: 02 July 2021

\section{References}

Bhaskar A, Bell A, Boivin M, et al. Consensus recommendations on dosing and administration of medical cannabis to treat chronic pain: results of a modified Delphi process. J Cannabis Res. https://doi.org/10.1186/ s42238-021-00073-1

Capano A, Weaver R, Burkman E. Evaluation of the effects of CBD hemp extract on opioid use and quality of life indicators in chronic pain patients: a prospective cohort study. Postgrad Med. 2020;132(1):56-61.

Cunetti L, Manzo L, Peyraube R, Arnaiz J, Curi L, Orihuela S. Chronic pain treatment with cannabidiol in kidney transplant patients in Uruguay. Transplant Proc. 2018:50(2):461-4.

Naftali T, Mechulam R, Lev LB, Konikoff FM. Cannabis for inflammatory bowel disease. Dig Dis. 2014;32(4):468-74.

Notcutt W, Price M, Miller R, et al. Initial experiences with medicinal extracts of cannabis for chronic pain: results from 34 ' $\mathrm{N}$ of 1 'studies. Anaesthesia. 2004;59(5):440-52. 
Pisanti S, Malfitano AM, Ciaglia E, et al. Cannabidiol: state of the art and new challenges for therapeutic applications. Pharmacol Ther. 2017;175:133-50.

St. Pierre M, Matthews L, Walsh Z. Cannabis education needs assessment among Canadian physicians-in-training. Complement Ther Med. 2020;49:102328. https://doi.org/10.1016/j.ctim.2020.102328.

Van De Donk T, Niesters M, Kowal MA, Olofsen E, Dahan A, Van Velzen M. An experimental randomized study on the analgesic effects of pharmaceutical-grade cannabis in chronic pain patients with fibromyalgia. Pain. 2019;160(4):860-9.

Wade DT, Robson P, House H, Makela P, Aram J. A preliminary controlled study to determine whether whole-plant cannabis extracts can improve intractable neurogenic symptoms. Clin Rehabil.

2003;17(1):21-9.

Xu DH, Cullen BD, Tang M, Fang Y. The effectiveness of topical cannabidiol oil in symptomatic relief of peripheral neuropathy of the lower extremities. Curr Pharm Biotechnol. 2019:21(5):390-400.

\section{Publisher's Note}

Springer Nature remains neutral with regard to jurisdictional claims in published maps and institutional affiliations.
Ready to submit your research? Choose BMC and benefit from:

- fast, convenient online submission

- thorough peer review by experienced researchers in your field

- rapid publication on acceptance

- support for research data, including large and complex data types

- gold Open Access which fosters wider collaboration and increased citations

- maximum visibility for your research: over 100M website views per year

At BMC, research is always in progress.

Learn more biomedcentral.com/submissions 